\title{
УТОЧНЕНИЕ РЕЗУЛЬТАТОВ ГЕОЛОГИЧЕСКОЙ ИНТЕРПРЕТАЦИИ МАЛОГЛУБИННЫХ СЕЙСМОРАЗВЕДОЧНЫХ ИССЛЕДОВАНИЙ ПО ДАННЫМ ШАХТНОЙ СЕЙСМОРАЗВЕДКИ В ПРЕДЕЛАХ КАМСКОГО ПРОГИБА ЮЖНОЙ ЧАСТИ ВКМКС
}

\author{
А.И. Никифорова \\ Горньй институт УрО РАН, г. Пермь
}

\begin{abstract}
Аннотация: Применение комплекса разноуровневых сейсморазведочных исследований с целью прогноза особенностей геологического строения водозащитной толщи ВКМКС, влияющих на её устойчивость, позволяет повысить достоверность и точность получаемых результатов. Участки с аномальными особенностями строения разреза, намеченные на этапе малоглубинных исследований, оцениваются и уточняются шахтной сейсмоакустикой.

Ключевые слова: Верхнекамское месторождение калийных и магниевых солей, литология, сейсморазведка, комплексный параметр, погрешность определения глубины.
\end{abstract}

Для детализации геологического строения соляной и надсоляной толщ, выявления локальных неоднородностей, осложняющих отработку калийной залежи Верхнекамского месторождения калийных солей (ВКМКС), применяется адаптивная, регулируемая и корректируемая в процессе получения результатов система комплексных сейсморазведочных исследований. Основная цель реализации подобной системы наблюденийлокализация с максимальной степенью детальности участков и интервалов «нарушенности» породного массива. Это возможно за счет ориентированного на конкретный объект сочетания пространственно-согласованных, различных по уровню детализации, а соответственно и по масштабам применения, методов. Степень детализации возрастает от малоглубинной сейсморазведки к инженерной, достигая максимума при исследованиях во внутренних точках среды (скважины, выработки). Все виды сейсморазведочных исследований базируются на технических решениях методики многократных перекрытий.

В структурном плане соляной толщи рассматриваемого участка южной части ВКМКС выделяется линейная региональная структура меридионального простирания Камский прогиб. С его восточным бортом отождествляется вероятное продолжение Соликамской зоны разрывных флексурно-складчатых дислокаций. В пределах изучаемой площади закартирован позднедевонский рифовый массив. Как показали ранее проведенные исследования $[1,3]$, этот факт также может оказывать негативное влияние на строение и свойства соляной толщи.

Работы по методике невзрывной малоглубинной сейсморазведки высокого разрешения выполнялись с 2008 г. По совокупности характерных признаков на профильных линиях выделены участки с предполагаемыми осложнениями геологического разреза (рис. 1). Для оценки степени негативных изменений и пространственной корреляции осложнений волнового поля построена карта распределения комплексного параметра в интервале 50 мс - 200 мс, что соответствует соляной и надсоляной толщам. Расчет его значений основан на совместном использовании независимых количественных характеристик волнового поля: частота, эффективная скорость, амплитуда, отношение сигнал\помеха. Функции, описывающие поведение указанных характеристик вдоль профиля, преобразуют в промежуточные, принимающие значения 0 или 1. Промежуточной функции присваивают нулевое значение, если на данном пикете исходная функция не выходит за доверительный интервал, и единицу - если выходит. Комплексный параметр представляет собой сумму промежуточных результатов, нормированную к заданному значению, обычно к 1.5 [4]. 


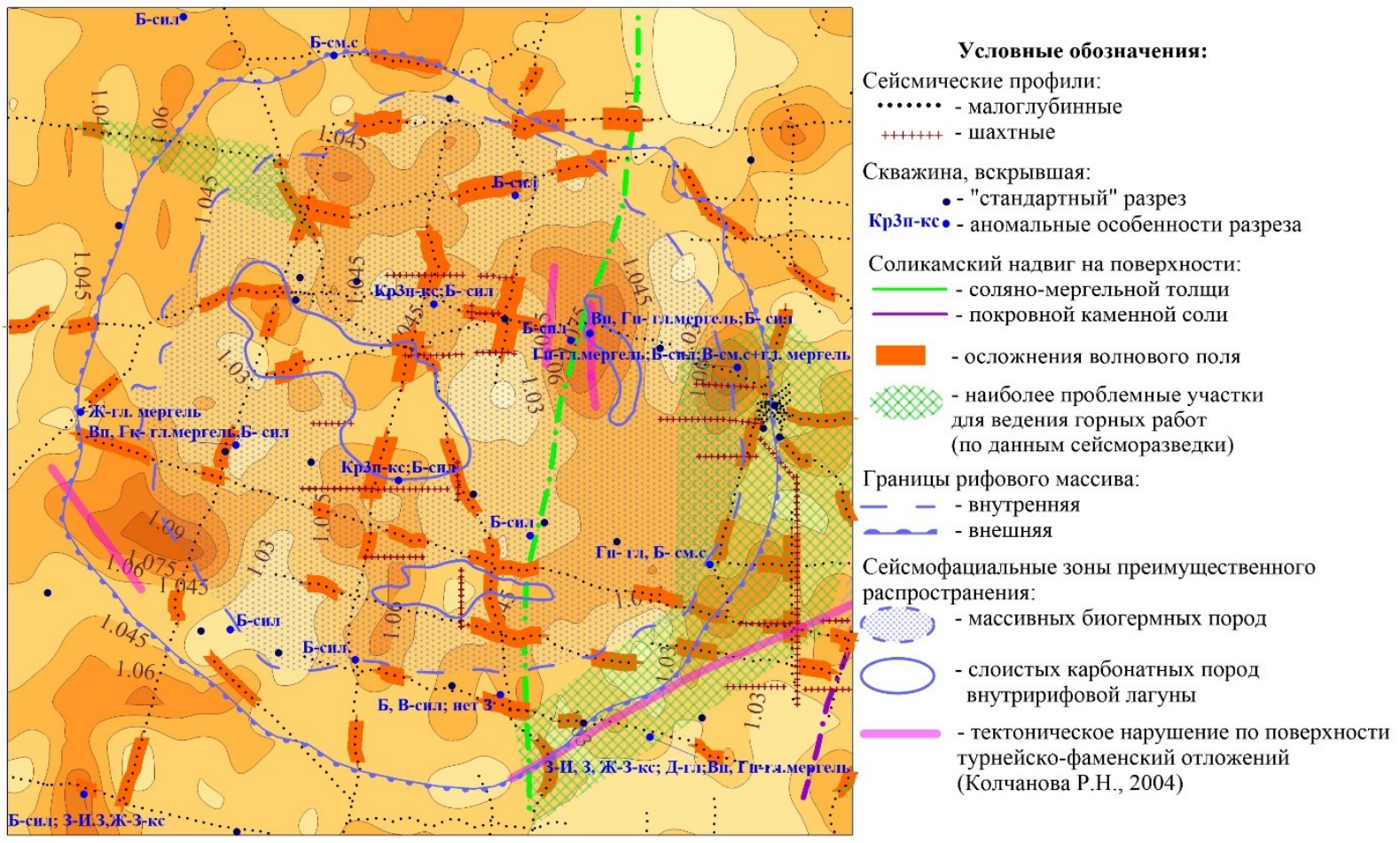

Рис. 1. Схема сопоставления распределения комплексного параметра с известными особенностями геологического строения

В качестве основных критериев классификации факторов, влияющих на формирование неоднородностей волнового поля, рассматривались структура волновой картины, ее интенсивность и оценки скоростей распространения упругих волн. Принимается, что на изменчивость гипсометрии осей синфазности преобладающее влияние оказывает структурный фактор, т. е. рельеф отражающей границы (рис. 2), а на интенсивность волнового поля (рис. 3) и значения скоростных параметров (рис. 4) - изменчивость петрофизических свойств исследуемого интервала геологического разреза. Подобная изменчивость может быть обусловлена как существенными вариациями физических свойств одной литологической разности, так и сменой литологии.

Объективность классификации в определенной мере подтверждается пространственными закономерностями в распределении осложнений волнового поля и структурно-физических параметров исследуемого интервала геологического разреза.

Наиболее значимые и обширные по разрезу участки осложнений волнового поля отмечаются по периферии рифа и плоскости смещения в зоне влияния Соликамского надвига. Основываясь на характере распределения эффективных скоростей, амплитуд и частот можно сделать вывод о преобладающем влиянии на формирование данных участков литологического фактора и второстепенном - структурного. На востоке предполагается ухудшение физико-механических свойств пород водозащитной толщи.

Для получения опережающей информации о строении горного массива на готовящихся к отработке площадях в подготовительных выработках рудника проведены шахтные сейсмоакустические исследования. В целом полученные результаты согласуются с наземными сейсморазведочными исследованиями. Расхождения в определении глубины залегания сильвинитовой пачки - отражающий горизонт (ОГ) Сил - не превышают 5\%, составляя в среднем $1 \%$ (рис. 5 ). 


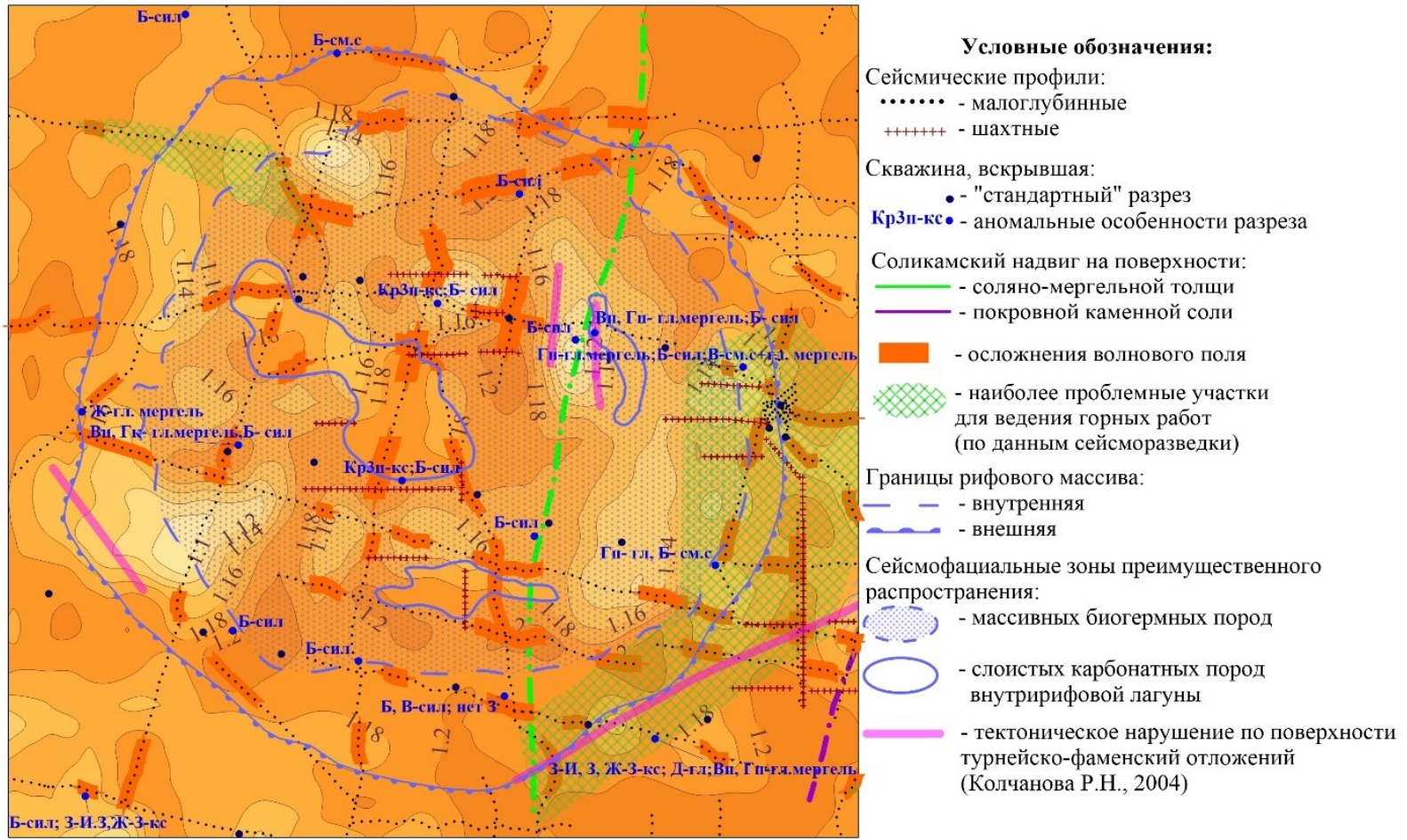

Рис. 2. Схема сопоставления распределения нормированных частот с известными особенностями геологического строения

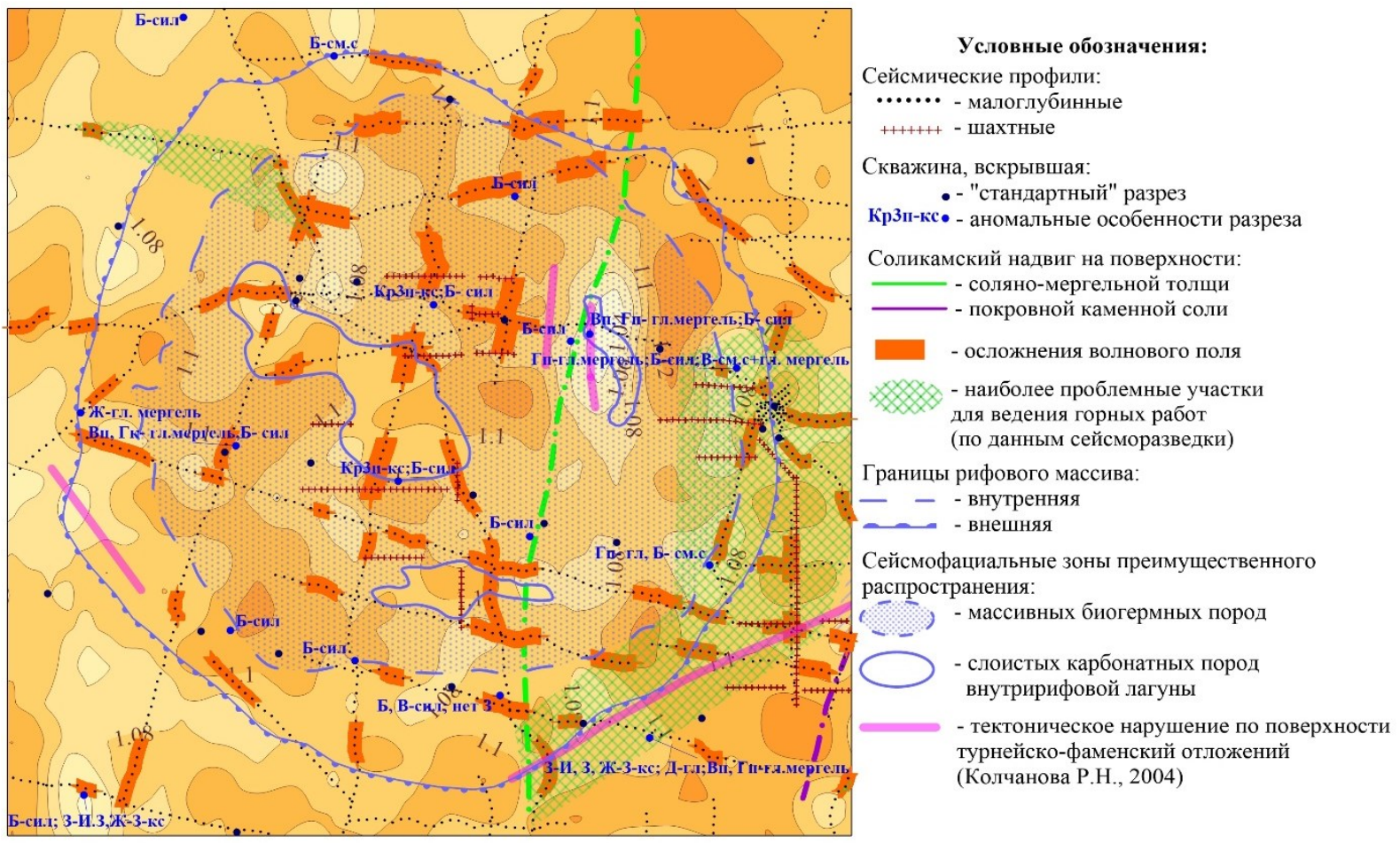

Рис. 3. Схема сопоставления распределения нормированных амплитуд с известными особенностями геологического строения

Подземная скважина, в которой установлена максимальная невязка, пробурена в аномальной зоне, намеченной по материалам малоглубинных сейсморазведочных исследований в 2010 г. Осложнение волнового поля выделяется в виде градиентной низкоскоростной зоны ( 200 м/c). Отмечается нарушение прослеживания ОГ. 


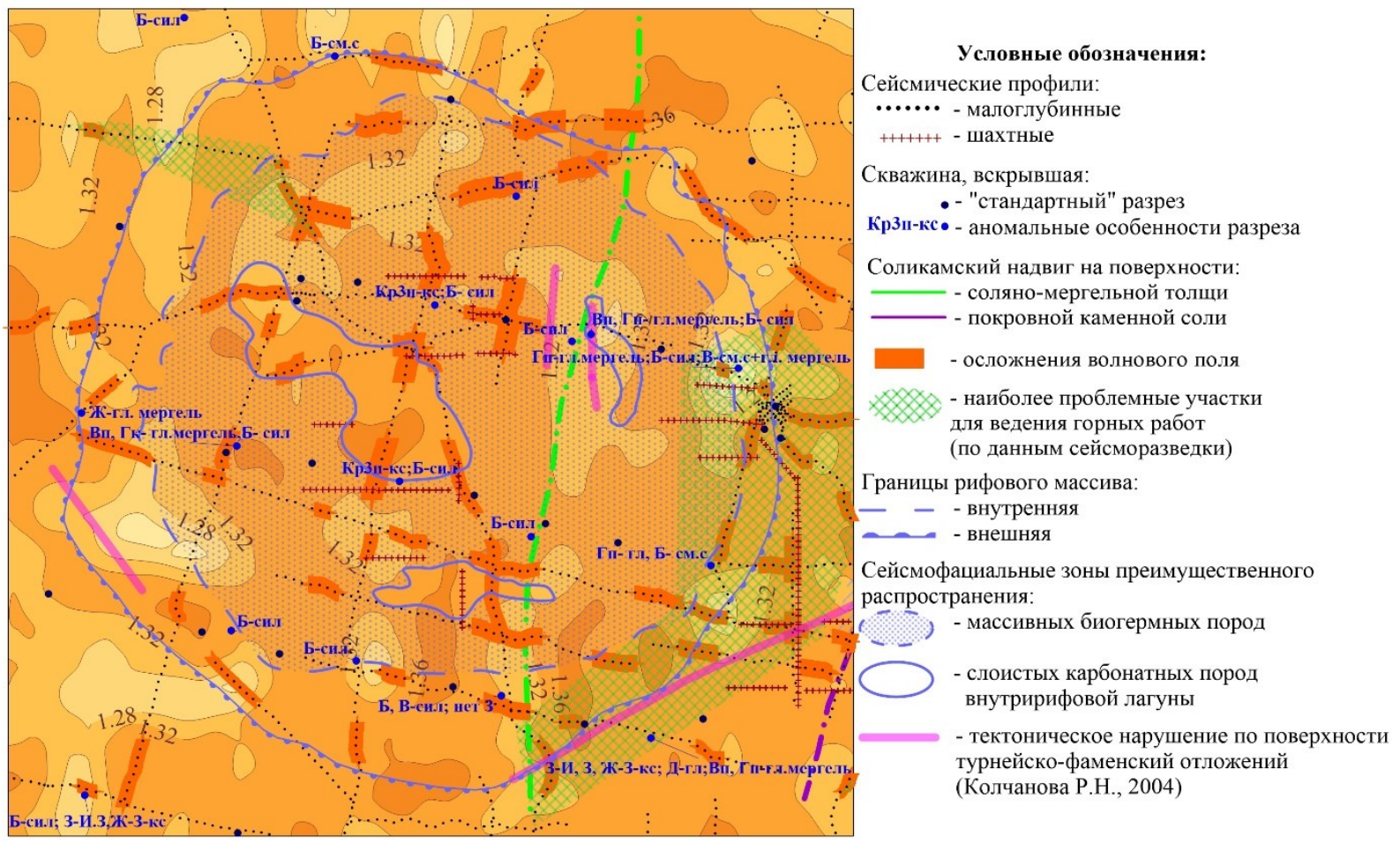

Рис. 4. Схема сопоставления распределения нормированных эффективных скоростей с известными особенностями геологического строения
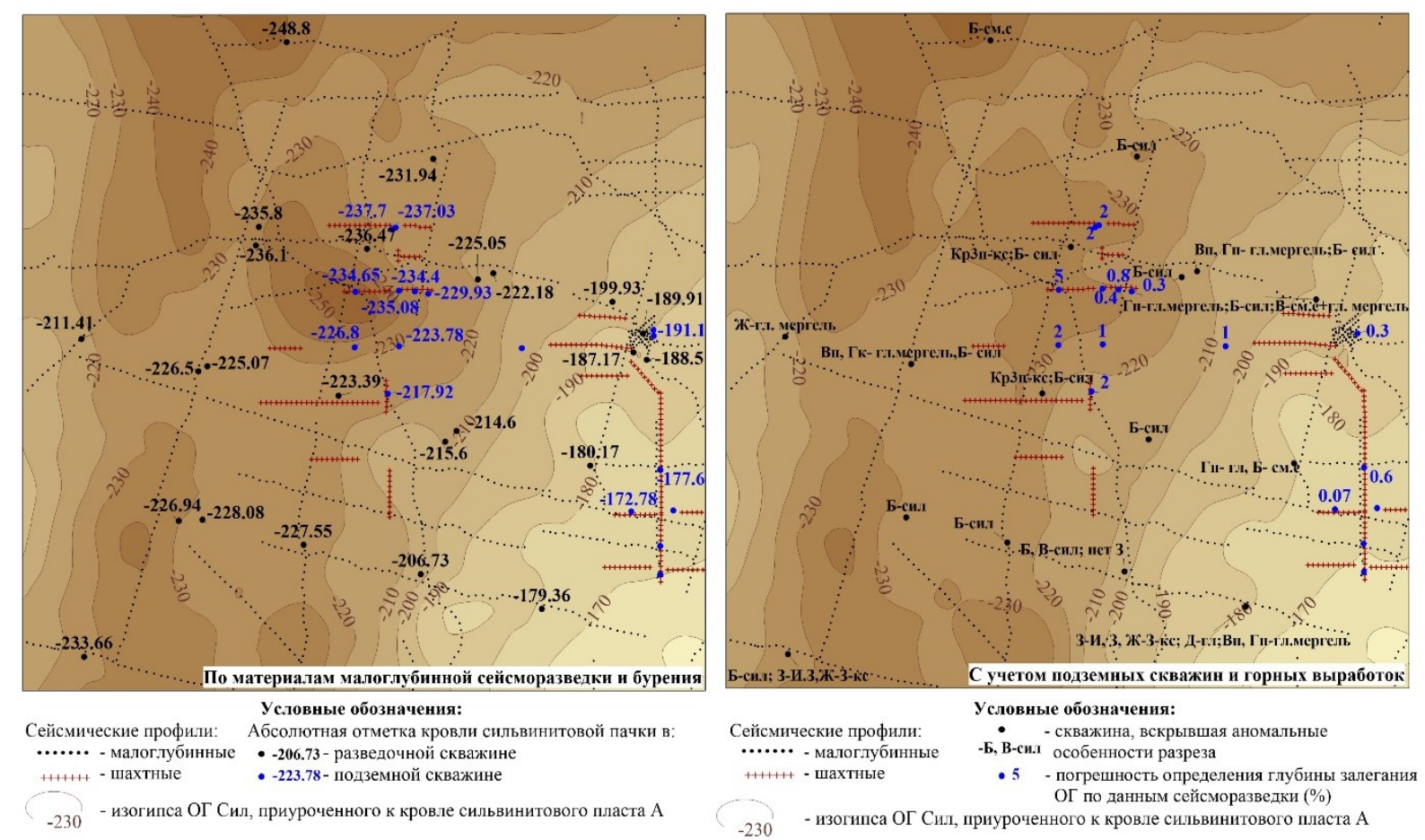

Рис. 5. Сопоставление структурных планов ОГ Сил

Скважина вскрыла пласт А сильвинитового состава, прослои каменной соли и глинистые прослойки 1-2 мм, фрагменты глинистых прослоев до 5 мм, а также единичные включения голубого галита. В кровле карналлитового пласта Б залегает 25 см пласт тонкослоистой глины с прослоями (1-2 см) тонкозернистой каменной соли. Перечисленные особенности определили формирование ОГ ниже стратиграфической границы. 
Распределение осложнений волнового поля представлено на рис. 6. Отмечается пространственная корреляция аномальных участков, намеченных по результатам малоглубинных исследований, с выделенными по материалам шахтной сейсморазведки. Наибольшая концентрация негативных изменений установлена в северо-восточной части площади, где в отложениях соляно-мергельной толщи проходит северная часть Соликамского надвига [2], а в турнейских отложениях, по данным нефтяной сейсморазведки, предполагается наличие грабенообразного прогиба. Здесь также по ранее выполненным исследованиям отмечается относительное снижение скоростных свойств в интервале продуктивной толщи.

Среди вновь выявленных особенностей следует отметить определенную пространственную согласованность осложнения волнового поля типа «плоскость скольжения» с положением Соликамского надвига. Интенсивность данного осложнения затухает в южном направлении.

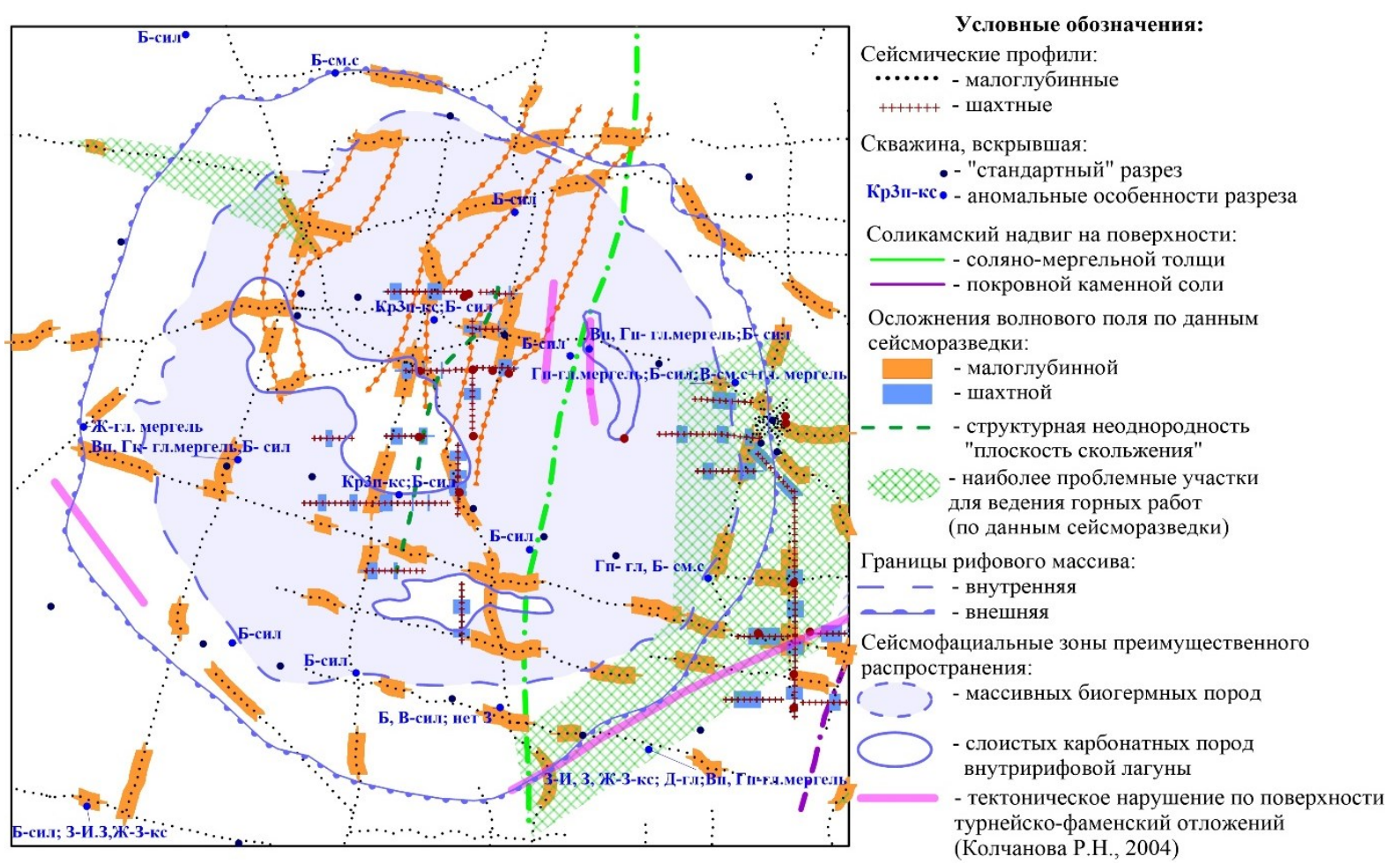

Рис. 6. Схема результатов качественной интерпретации

Исследование выполнено при финансовой поддержке Программы ФНИ, проект № 0422-2019-0146-С-02 (регистраичонный номер темь НИОКТР: AAAA-A18-118040690028-5)

\section{БИБЛИОГРАФИЧЕСКИЙ СПИСОК}

1. Барях А.А., Санфиров И.А., Еремина Н.А., Кудряшов А.И., Прийма Г.Ю. О влиянии рифогенных образований на структуру верхних этажей осадочного чехла // Доклады РАН. - 1998. - Т. 363, № 3. - С. 371-347.

2. Петротектонические основы безопасной эксплуатации Верхнекамского месторождения калийномагниевых солей / под ред. Н.М. Джиноридзе. - СПб; Соликамск, 2000. - 400 с.

3. Никифорова А.И., Санфиров И.А., Калашникова М.М. Региональная оценка сложности сейсмогеологического строения шахтных полей верхнекамского месторождения // Горный информационноаналитический бюллетень (научно-технический журнал). - 2014. - № 1. - С. 91-97.

4. Санфиров И.А., Пригара А.М. Использование динамических характеристик сейсмических записей для уточнения прочностных характеристик массивов горных пород // Горное эхо. - 2002. - № 3 (9). - С. 31-33. 